\title{
Induction of Ornithine Decarboxylase as a Possible Mediator of Seizure-Elicited Changes in Genomic Expression in Rat Hippocampus
}

\author{
Michel Baudry, Gary Lynch, and Christine Gall* \\ Center for the Neurobiology of Learning and Memory and the *Department of Anatomy, University of California, \\ Invine, California 92717
}

\begin{abstract}
Small electrolytic lesions placed in the hilus of the dentate gyrus have been shown to induce behavioral seizures, an elevation in the concentration of the opioid peptide enkephalin, and an increase in the transcription of the gene coding for the peptide precursor of enkephalin. Since polyamines and ornithine decarboxylase (ODC), the rate-limiting enzyme in their synthesis, have been shown to play critical roles in the growth and differentiation of several types of tissue, we tested for changes in ODC activity at various times following the initiation of seizures. ODC activity is significantly increased $3 \mathrm{hr}$ after the lesions, reaches maximal (50-fold) levels about $12 \mathrm{hr}$ later, and returns to control values after $48 \mathrm{hr}$. The increase occurs in both hippocampi following unilateral electrolytic lesions, is blocked by treatments that suppress limbic seizures, and does not occur after lesions that fail to elicit seizures; accordingly, we conclude that the increase in ODC activity results from epileptiform activity rather than some other consequence of the hilar lesion (e.g., deafferentation). The increase in ODC activity precedes the increase in the amount of mRNA coding for the enkephalin prohormone, which, in turn, precedes the increase in enkephalin levels. These results are consistent with the hypothesis that the early induction of ODC following the initiation of seizures leads to an alteration in genomic expression, which, in turn, changes neuropeptide levels. Adult brains thus appear to possess trophic responses of a type found in a variety of developing cell types and organs, and the possibility exists that these are involved in the control of seizure susceptibility.
\end{abstract}

Recent studies have shown that adult neurons in both peripheral and central nervous systems maintain an unexpected ability to modify the expression of their transmitter phenotypes in response to a variety of factors such as hormones or prolonged depolarization (see Black et al., 1984, for a review). Although it has been established that the changes in phenotypic characters sometimes result from an alteration of genomic expression (Wolfson et al., 1985), the intracellular signals that mediate the effects of extracellular physiological-chemical variables on gene expression are as yet unknown. Recently, one of us reported that a small electrolytic lesion placed in the hilar region of the dentate gyrus causes recurrent limbic seizure activity lasting several hours, and that this is followed by perturbations in the concentration of certain neuroactive peptides in the hippocam-

\footnotetext{
Received Dec. 9, 1985; revised Mar. 18, 1986; accepted May 15, 1986.

This work was supported by Grants NS-18427 from the NINCDS to M.B., AFOSR 82-0116 to G.L., and BNS 8417098 from the NSF to C.G. C.G. was also supported by the RCDA (NS00915). We wish to thank Jackie Porter for her expert secretarial assistance and Rowland Davis for helpful discussions.

Correspondence should be addressed to M. Baudry, Center for the Neurobiology of Learning and Memory, University of California, Irvine, CA 92717.

Copyright (1986 Suciety for Neuroscience 0270-6474/86/123430-06\$02.00/0
}

pal formation. Specifically, enkephalin immunoreactivity in the hippocampal mossy fiber axonal system increases dramatically following seizure-inducing focal lesions in rats, while dynorphin and, in mouse, cholecystokinin immunoreactivity in this same axonal system are decreased (Gall et al., 1981a, b, 1984, and unpublished observations). The increase in mossy fiber enkephalin is preceded by an increase in the production of preproenkephalin mRNA (White et al., in press). Other investigators have reported alterations in hippocampal peptide content following seizures elicited by kainic acid, amygdaloid kindling, and repeated electroconvulsive shocks (Hong et al., 1980, 1985a-c; Iadarola et al., 1985).

There is a considerable body of evidence pointing to the conclusion that polyamines serve as intracellular mediators for a number of trophic influences on growth and differentiation (Bachrach, 1976; Canellakis et al., 1979). Moreover, it has been reported that electroconvulsive shock causes an increase in the activity of brain ornithine decarboxylase (ODC), the rate-limiting enzyme in polyamine synthesis (Pajunen et al., 1978). This suggests the possibility that ODC induction may represent a link between limbic seizures induced by focal lesions and the increased synthesis of preproenkephalin mRNA and enkephalin in the mossy fibers. The results of the present experiments provide correlational evidence for this hypothesis by showing that hilus lesions cause a 50-fold increase in hippocampal ODC activity, that this effect precedes the alterations in mRNA and peptide concentrations, and that suppression of the seizures blocks the increases in ODC activity and pcptide levels. Besides pointing to a possible mediator of the effects of limbic seizures on the balance of neuropeptides in hippocampus, the findings suggest a relatively simple paradigm with which to search for factors that might regulate genomic expression in adult neurons.

\section{Materials and Methods}

Male Sprague-Dawley rats weighing 200-300 gm were used in this study. They were kept in a constant temperature of $23^{\circ} \mathrm{C}$, with access to food and water ad libitum.

\section{Experimental treatments}

Several groups of experimental animals were prepared. In the principal (hilus lesion) experimental group, animals were anesthetized with ketamine and xylazine $(5 \mathrm{mg}$ ketamine and $1 \mathrm{mg}$ xylazine/100 gm body weight), and an electrolytic lesion was placed unilaterally in the hilus of the dentate gyrus using an insulated stainless steel wire and anodal current of $0.8 \mathrm{~mA}$ for $7 \mathrm{sec}$. Paired control animals were either simply anesthetized (anesthetic controls) or treated as sham-operates in which the electrode was lowered into the cortex, above the hippocampus, but no current was passed. Approximately 1-2 hr after surgery, the fully awake hilus lesion rats exhibited seizures. As with the motor seizures described by Racine (1972) to accompany kindled limbic seizures, these initially involved episodes of forelimb clonus, "wet-dog shakes," facial tremor, and nodding. With time, the severity of the motor seizures 


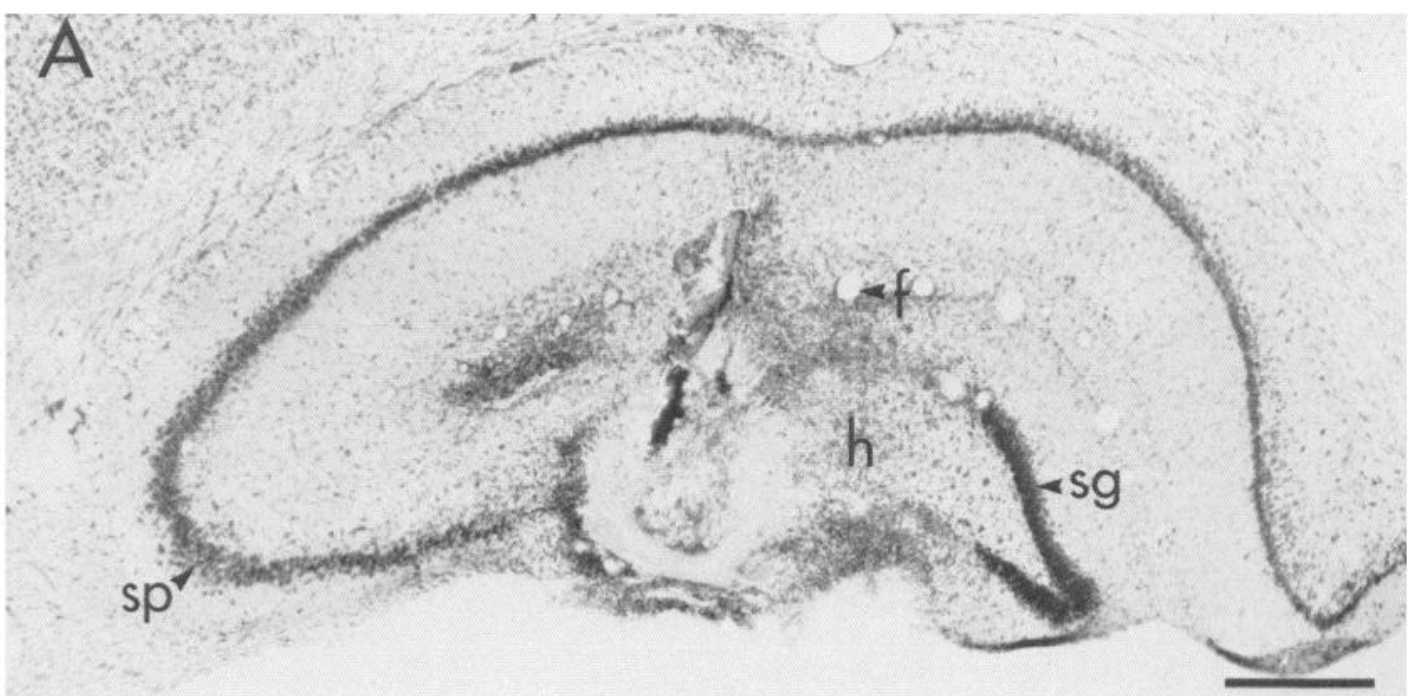

B
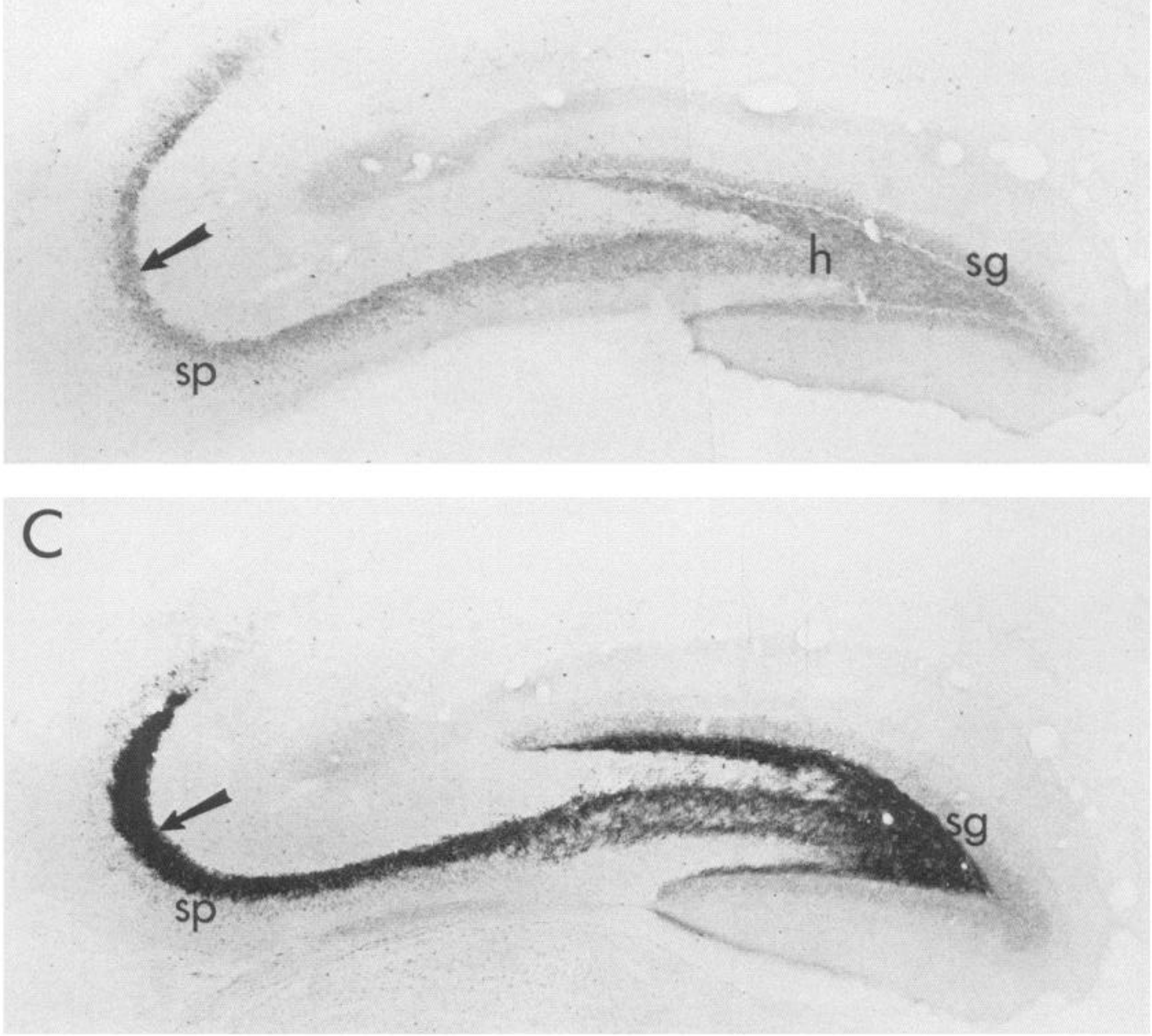

Figure 1. A, Photomicrograph of a Nissl-stained coronal section through the center of a lesion of the type used in the present study. $B$ and $C$, Distribution and density of peroxidase-antiperoxidase- (PAP) labeled enkephalin-like immunoreactivity in coronal sections through the rostral hippocampus of $(B)$ an untreated rat and $(C)$ a paired hilus lesion rat (killed $4 \mathrm{~d}$ postlesion, contralateral hippocampus shown). Note the large and selective increase in enkephalin-like immunoreactivity within the hippocampal mossy fiber axonal system (arrows) following this treatment. $f$, Hippocampal fissure; $h$, dentate gyrus hilus; sg, stratum granulosum; sp, stratum pyramidale. Calibration bar, $400 \mu \mathrm{m}(A), 350 \mu \mathrm{m}(B$ and $C)$. 


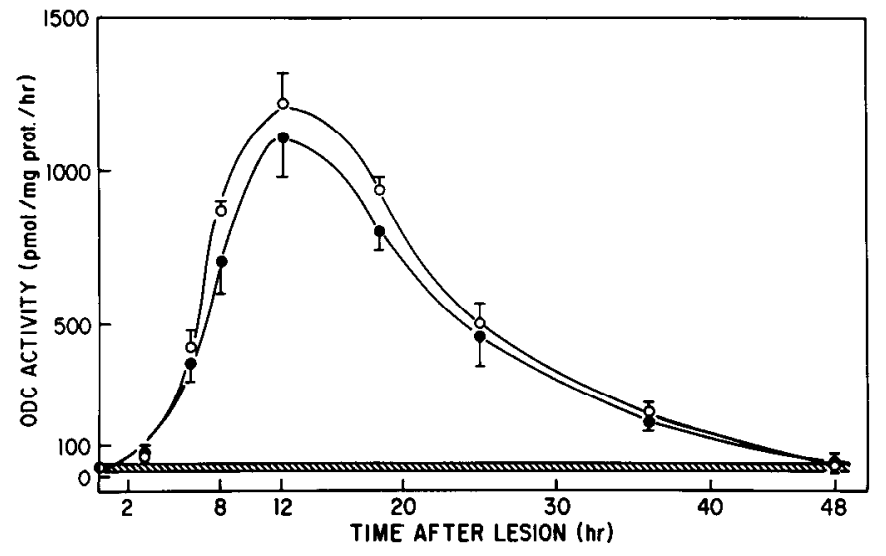

Figure 2. ODC activity in hippocampus of rats killed at various intervals following a unilateral hilus lesion. ODC activity was determined in hippocampus contralateral (open circles) and ipsilateral (closed circles) to the lesion at the indicated postlesion intervals. Results are expressed in pmoles of ${ }^{14} \mathrm{CO}_{2}$ formed $/ \mathrm{mg}$ protein $/ \mathrm{hr}$ and are means \pm SEM of 3-8 experiments. The shaded area represents the values (means \pm SEM) found in control or sham-operated animals.

generally escalated to include rearing with forelimb clonus and, occasionally, rearing and falling. These bouts typically occurred episodically for $6-10 \mathrm{hr}$.

Two additional experimental lesions were performed. Under ketamine/xylazine anesthesia, either 1 eye was removed or a large, unilateral electrolytic lesion was placed in the entorhinal cortex. These treatments deafferent the contralateral superior colliculus and ipsilateral hippocampus, respectively. In agreement with a previous report (Dasheiff and McNamara, 1982), 1-2 hr after the placement of the entorhinal cortex lesion, the animals began to exhibit motor seizure activity which was similar to, but less severe and shorter lived than that seen following hilus lesions. Unilateral eye removal did not produce seizures.

An additional 4 animals receiving small hilar lesions were anesthetized with sodium pentobarbital $1 / 2 \mathrm{hr}$ before lesion placement and were maintained under deep pentobarbital anesthesia until they were killed 8 or $12 \mathrm{hr}$ later. This treatment effectively blocked the occurrence of seizures. Finally, the adrenal gland was removed bilaterally in 2 rats 1 week prior to the hilus lesion; drinking water was replaced with $0.9 \%$ saline from the time of adrenalectomy until these and 2 untreated control rats were killed.

\section{Assay for ODC activity}

At various intervals after lesion placement, the unanesthetized rats were killed by decapitation, and their brains rapidly removed and dissected on ice. Individual hippocampi, cortical samples, and cerebellar samples were each homogenized in $1 \mathrm{ml}$ of cold $25 \mathrm{~mm}$ Tris- $\mathrm{HCl}$ buffer, $\mathrm{pH} \mathrm{7.4,}$ containing $0.1 \mathrm{~mm}$ EDTA, $5 \mathrm{~mm}$ dithiothreitol (dTT), and $0.1 \mathrm{~mm}$ pyridoxal-5'-phosphate (P-5'-P). Individual superior colliculi were homogenized in $0.5 \mathrm{ml}$. The homogenates were centrifuged at $48,000 \times$ $g$ for $20 \mathrm{~min}$ at $4^{\circ} \mathrm{C}$ and aliquots of the supernatants were assayed for ODC activity using a modified version of the technique described by Russell and Snyder (1968). The incubation mixture consisted of undialyzed supernatant, $0.1 \mathrm{~mm}$ EDTA, $5 \mathrm{~mm}$ dTT, $0.1 \mathrm{~mm}$ P-5'-P and 50 $\mu \mathrm{M}$ D,L- ${ }^{14} \mathrm{C}$-ornithine (ICN, Irvinc, CA, spccific activity, $5-6 \mathrm{mCi} / \mathrm{mmol}$ ). Incubations were carried out for $60 \mathrm{~min}$ at $30^{\circ} \mathrm{C}$ in glass tubes sealed with serum bottle caps with attached plastic wells containing filter papers soaked in an alkaline solution (NCS, Amersham, UK). The reactions were stopped by the addition of $0.5 \mathrm{ml}$ of $10 \%$ trichloroacetic acid. The tubes were then incubated for a further $30 \mathrm{~min}$ at $30^{\circ} \mathrm{C}$, to allow for complete absorption of the ${ }^{14} \mathrm{CO}_{2}$ into the filter papers, and the radioactivity of the filters was determined by liquid scintillation counting. "Blanks" consisted of incubations performed in the absence of added tissue. The protein content of each sample was determined by the method of Bradford (1976) with BSA as a standard. Results are expressed as picomoles of ${ }^{14} \mathrm{CO}_{2}$ formed $/ \mathrm{mg}$ protein $/ \mathrm{hr}$.

\section{Results}

Figure 1 illustrates both the type of hilar lesion used in the present experiments as well as the magnitude and location of
Table 1. Comparison of the effect of entorhinal cortex and hilus lesions on ODC activity in rat hippocampus

\begin{tabular}{lll} 
& Hilus lesion & $\begin{array}{l}\text { Entorhinal cortex } \\
\text { lesion }\end{array}$ \\
\hline Lesion side & $1106 \pm 134$ & $442 \pm 50^{*}$ \\
Contralateral side & $1219 \pm 109$ & $385 \pm 114^{*}$
\end{tabular}

Elcctrolytic lesions werc placed unilaterally in the hilus or in the entorhinal cortex. Animals were killed $12 \mathrm{hr}$ later and ODC activity was measured in the soluble fractions of hippocampi ipsilateral and contralateral to the lesion side. Results are expressed as pmoles of ${ }^{14} \mathrm{CO}_{2}$ formed $/ \mathrm{mg}$ protein $/ \mathrm{hr}$ and are means \pm SEM of 4 experiments. Values found in control, unoperated, or sham-operated animals are $25 \pm 2 \mathrm{pmol} / \mathrm{mg}$ protein $/ \mathrm{hr}$.

$* p<0.01$ (Student's $t$ test).

the increased enkephalin immunoreactivity seen at $96 \mathrm{hr}$ postlesion.

\section{Changes in ODC activity at various intervals after lesions to the hilus}

ODC activity in both hippocampi of hilus lesion animals was measured at various times after lesion placement and compared to values obtained from unoperated (anesthetic control) rats (Fig. 2). ODC activity was significantly increased in hippocampus bilaterally $3 \mathrm{hr}$ after the lesions were performed, and reached a maximum level of 50 times greater than control by $12 \mathrm{hr}$ postlesion; it was still elevated at $24 \mathrm{hr}$ but returned to control values by $48 \mathrm{hr}$ postlesion. In all cases, the increase was slightly greater in the hippocampus contralateral to the lesion. No increase in ODC activity was observed in animals receiving anesthetics alone, or in "sham-operated" rats in which an electrode was lowered into cortex above the hippocampus. When hippocampi wcre longitudinally divided into dentate/CA and $\mathrm{CA}_{3}$ regions, comparable increases in ODC activity were obtained in both subfields; in contrast, values in the cerebellum of hilus lesion animals were not significantly different from those of controls at any time following the lesion (data not shown).

\section{Changes in hippocampal ODC activity after entorhinal cortex lesions}

ODC was assayed in both hippocampi following unilateral electrolytic lesions of the entorhinal cortex. Twelve hours after lesion placement, ODC activity was reliably increased as compared to that of control rats; however, the increase was significantly less than that obtained in hilus lesioned animals (Table I). In order to discriminate between the effects of deafferentation from those of seizure, we measured ODC activity in superior colliculus of unilaterally enucleated rats. Twelve hours postenucleation, ODC activity was not modified in superior colliculus, whereas it was slightly elevated in this brain area following hilus lesion (data not shown).

\section{Effect of pentobarbital treatment and adrenalectomy on the seizure-elicited increase in $O D C$ activity}

Hippocampal ODC was measured in rats that were maintained under deep sodium pentobarbital anesthesia for 8 or $12 \mathrm{hr}$ following unilateral lesions of the hilus (Fig. 3). Under these conditions, the elevation of ODC activity was greatly reduced from that seen in normal hilus lesion rats (in which motor seizures were observed). It is interesting to note that the treatment with pentobarbital prevented the increase in ODC activity more completely in the hippocampus contralateral $(90 \%)$ than that ipsilateral $(50 \%)$ to the lesion. The presence of the adrenal gland was not necessary for the lesion-induced increase in hippocampal ODC. The effect observed in rats adrenalectomized 1 week before the lesion was comparable to that in animals with intact adrenals (data not shown). 


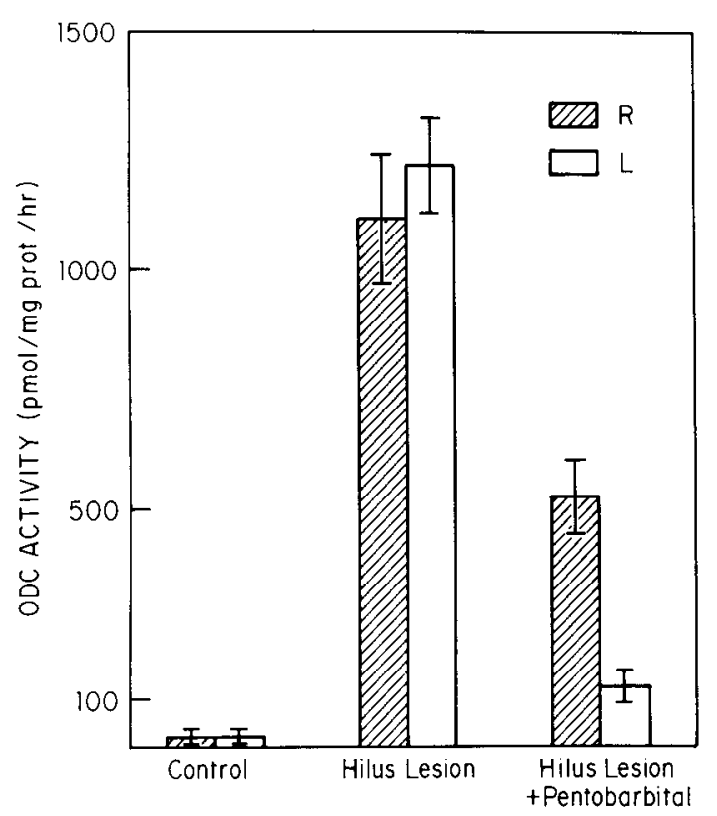

Figure 3. Effect of pentobarbital on hilus lesion induction of ODC activity in rat hippocampus. Electrolytic lesions were placed unilaterally in the right $(R)$ hilus of the dentate gyrus. One group of rats was lesioned and maintained under pentobarbital until killed (8-10 hr after the lesion). ODC activity was measured in the right (lesion side, $R$ ) and left $(L)$ hippocampus. Results are means \pm SEM of 4-6 experiments. (Statistical significance: $R$ or $L$ hilus lesion vs $R$ or $L$ hilus lesion + pentobarbital, $p<0.005 ; R$ vs $L$ hilus lesion + pentobarbital, $p<0.01$; $R$ hilus lesion + pentobarbital vs control, $p<0.01 ; L$ hilus lesion + pentobarbital vs control, not significant; Student's $t$ test.)

Comparison of the ODC time course with behavioral, physiological, and anatomical effects of hilus lesions

The hilus lesions initiate a number of processes that are characterized by different time courses (Fig. 4). About 1-2 hr after the lesion, the animals begin to develop behavioral seizures that generally last at least 6 , and occasionally up to $10 \mathrm{hr}$. Throughout the period of behavioral seizures, recordings of hippocampal EEG show alternating periods of epileptiform discharges and depressed activity. By $12 \mathrm{hr}$, the EEG is fairly normal, with only occasional, isolated, large spikes. It has been shown previously that opiate peptide levels in the hippocampal mossy fibers go through a biphasic fluctuation. Initially (6-12 hr postlesion), enkephalin immunoreactivity in the mossy fibers is greatly decreased; thereafter, immunoreactivity for the peptide increases, reaching normal levels by about $18 \mathrm{hr}$ postlesion and maximum levels by approximately $72 \mathrm{hr}$ (Fig. 4; Gall et al., in press; Pico et al., 1985). The concentration of preproenkephalin mRNA in the dentate gyrus has been found to be elevated above the norm as early as $12 \mathrm{hr}$ postlesion, and to be further increased at both 24 and $30 \mathrm{hr}$ postlesion (White et al., in press). Thus the increase in ODC activity occurs after the onset of seizures but precedes the increase in both preproenkephalin mRNA and enkephalin content.

\section{Discussion}

The present results demonstrate that the activity of ODC, the polyamine-biosynthetic enzyme considered to be involved in the regulation of genomic expression, increases dramatically bilaterally in hippocampus after unilateral lesion of the dentate gyrus hilus. Several arguments point to the conclusion that the limbic seizures induced by the lesion are responsible for the observed increase in ODC activity. First, the unilateral hilus lesions were quite small and would have produced only a slight

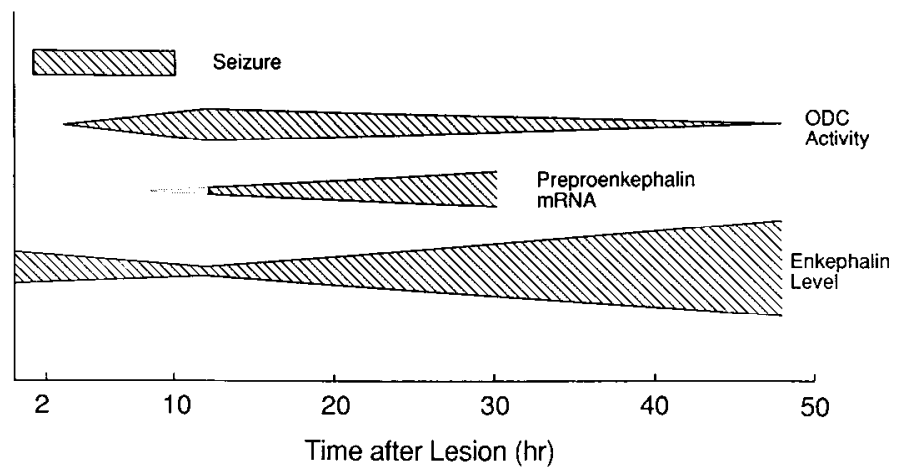

Figure 4. Comparison of the time courses for various parameters affected by hilus lesion. The various changes are summarized in a semiquantitative fashion. The period of seizure activity was determined by behavioral observation and EEG recording. Data for the preproenkephalin mRNA are from White et al. (in press). The dotted line indicates that the precise time course for the changes occurring before $12 \mathrm{hr}$ postlesion is still under investigation. Data on the changes in mossy fiber enkephalin content are from the immunohistochemical and radioimmunoassay observations of Gall (1984, and unpublished observations).

deafferentation of the contralateral hippocampus. By contrast, the increase in ODC activity was bilateral in hippocampus, being slightly larger on the side contralateral to the lesion, which suggests that the physiological, rather than the anatomical, effects of the lesions were responsible for activating ODC. Sccond, very large lesions of the entorhinal cortex, which can be expected to produce much more degeneration and denervation in hippocampus, but result in more modest seizures than contralateral hilar lesions, induced a smaller increase in ODC activity than did hilar lesions. Third, eye removal had no detectable effect on ODC in the superior colliculus despite the massive denervation it causes in that structure. Finally, suppression of the seizures with pentobarbital greatly reduced the increase in ODC activity (in this regard, it is interesting to note that in a few animals for which pentobarbital failed to prevent the seizures, ODC activity was increased as in animals not treated with the drug).

The results from the lesion control groups make the further point that the mechanisms by which seizures result in an increase in ODC activity must be reasonably selective. That is, we can assume that removal of the optic tract projections by enucleation causes severe disturbances in the chemistry and physiology of the superior colliculus, yet this manipulation had no detectable effect on ODC activity.

Little can be said about the chemical changes associated with seizures that might activate ODC. In other systems, it has been proposed that increases in cAMP or in intracellular calcium are necessary steps for ODC induction (Gibbs et al., 1980; Russell et al., 1976). The possibility has recently been raised that activation of protein kinase $C$ and of calmodulin-dependent enzymes are involved (Otani et al., 1985). It is not unlikely that seizures activate all these processes. Studies are now in progress to determine whether the induction of ODC can be obtained by various manipulations of in vitro slices of hippocampus. This preparation would allow us to use pharmacological manipulations to explore possible links between intense physiological activity and increased ODC activity.

An extensive literature indicates that increased polyamine levels, caused by high levels of ODC, are associated with, and sometimes causally related to, a number of growth processes, including mitosis, differentation, and hypertrophy (Canellakis et al., 1979; Pegg and McCann, 1981; Russell and Snyder, 1968). Thus, a variety of growth factors or hormones induces both rapid activation of ODC and various growth responses in several 
tissues or cells in culture (Carpenter and Cohen, 1979; Greene and McGuire, 1978; Lewis et al., 1978; Janne and Raina, 1969; Russell and Durie, 1978). Conversely, inhibition of ODC activity has been shown to disrupt both proliferative and postmitotic synthetic processes in the CNS and elsewhere (Bartolome et al., 1985; Slotkin et al., 1985). In addition, polyamine biosynthesis has been shown to be required for the survival of sympathetic neurons following axonal injury (Gilad and Gilad, 1983) and it has been suggested that ODC induction is involved in triggering a "regeneration program" following axotomy of the facial nerve (Tetzlaff and Kreutzberg, 1985).

The time course for the increase in ODC activity in hippocampus following seizures is comparable to that observed in peripheral tissues in response to various manipulations (Carpenter and Cohen, 1979; Greene and McGuire, 1978; Lewis et al., 1978; Russell and Durie, 1978). The increase in ODC activity occurs after seizures have begun, but most probably before the increase in hippocampal preproenkephalin mRNA and certainly before the increase in enkephalin concentrations. Moreover, the suppression of seizures following the hilus lesion prevents both the increase in ODC activity and the alteration in neuropeptide levels. In nearly all peripheral tissue systems so far examined, it has been shown that elevations in ODC activity are generally due to the synthesis of new enzyme (Russell and Haddox, 1979), and it is reasonable to assume that this applies also to our experiments. Therefore, the data obtained in the present study, considered in conjunction with the postulated roles of polyamines in other systems, are consistent with the hypothesis that activation of the ODC system may be part of a sequence of steps leading from recurrent seizures to increased enkephalin synthesis. This hypothesis makes a number of specific testable predictions, the most important of which is that inhibition of ODC activity should block the effects of seizures on neuropeptide levels. Experiments are now in progress to test this point.

Independent of the possibility of a causal relationship between increased ODC activity and increased enkephalin synthesis, the fact that both processes can be stimulated by an episode of recurrent seizure activity demonstrates that the same biochemical machinery proposed as being responsible for promoting growth and differentiation in developing tissues can be activated by physiological activity in the adult CNS. It is interesting to note that this machinery loses its responsiveness to several kinds of stimuli (e.g., monoamines) in adult neurons (Morris et al., 1983). It is also evident that a limited number of genes respond to the recurrent seizures induced by hilus lesions, since only a small number of mRNAs are increased under these conditions (J. McKelvy, personal communication). This suggests either that a small number of genes remain "open" in adult neurons, or that other factors necessary for altering a large fraction of the gene pool are not affected by the seizures. It will be interesting to test whether other physiological events or processes thought to involve trophic factors in the adult nervous system induce ODC activity as well.

Additional work is also needed on the physiological conditions needed for ODC activation. The possibility exists that the effects seen after seizures are exaggerations of events occurring with less extreme stimulation. If so, then the ODC mechanism might provide the biochemical intermediate between neuronal activity and regulation of genomic expression hypothesized to explain structural changes in brain resulting from expcrience.

Finally, the present results have clear implications for hypotheses about the etiology of epilepsy. With the paradigm we used, a recurrent seizure episode was found to increase the activity of $O D C$, the rate-limiting enzyme in the synthesis of polyamines, substances that have been proposed to influence genomic expression. In turn, the neuropeptides that are altered by the same treatment are known to exert potent effects on epilep- tiform activity. Specifically, enkephalin promotes and cholecystokinin retards the development of seizures (Elazar et al., 1979; Frenk et al., 1978; Zetler, 1981). This raises the possibility that an initial seizure, by inducing ODC, increases the enkephalin levels and thereby the probability of subsequent epileptiform activity. In this way, a cycle of seizures-ODC activationpeptide changes-seizures-ODC activation, etc. - would emerge. It will be of interest to test for the effects of inhibition of ODC activity on the development of seizure susceptibility following epileptiform episodes.

\section{References}

Bachrach, U. (1963) Function of Naturally Occurring Polyamines, Academic, New York.

Bartolome, J. U., L. Schweitzer, T. A. Slotkin, and J. V. Nadler (1985) Impaired development of cerebellar cortex in rats treated postnatally with $\alpha$-difluoromethylornithine. Neuroscience 15: 203-213.

Black, I. B., J. E. Adler, C. F. Dreyfus, G. M. Jonakait, D. M. Katz, E. F. LaGamma, and K. M. Markey (1984) Neurotransmitter plasticity at the molecular level. Science 225: 1266-1270.

Bradford, M. (1976) A rapid and sensitive method for the quantitation of microgram quantities of protein utilizing the principle of proteindye binding. Anal. Biochem. 72: 248-254.

Canellakis, E. S., D. Viceps-Madore, D. A. Kyriakidis, and J. S. Heller (1979) The regulation and function of ornithine decarboxylase and of the polyamines. Curr. Top. Cell. Regul. 15: 155-202.

Carpenter, G., and S. Cohen (1979) Epidermal growth factor. Annu. Rev. Biochem. 48: 193-216.

Dasheiff, R. M., and J. O. McNamara (1982) Electrolytic entorhinal lesions cause seizures. Brain Res. 231: 444-450.

Elazar, Z., E. Motles, Y. Wly, and R. Simantov (1979) Acute tolerance to the excitatory effect of enkephalin microinjections into hippocampus. Life Sci. 24: 541-548.

Frenk, H., G. Urca, and J. C. Liebeskind (1978) Epileptic properties of leucine- and methionine-enkephalin: Comparison with morphine and reversibility by naloxone. Brain Res. 147: 327-337.

Gall, C. (1984) Seizure-producing treatments result in increased enkephalin and decreased cholecystokinin immunoreactivity in mossy fibers. Soc. Neurosci. Abstr. 10:112.

Gall, C., N. Brecha, H. J. Karten, and K.-J. Chang (1981a) Localization of enkephalin-like immunorcactivity to identificd axonal and neuronal populations of the rat hippocampus. J. Comp. Neurol. 198: 335-350.

Gall, C., N. Brecha, K.-J. Chang, and H. J. Karten (1981b) Localization of increased hippocampal leucine enkephalin-like immunoreactivity following hilar lesions in the adult rat. Soc. Neurosci. Abstr. 7: 94.

Gall, C., R. Pico, and J. Lauterborn (in press) Focal hippocampal lesions induce seizures and long-lasting changes in mossy fiber enkephalin and CCK immunoreactivity. Peptides.

Gibbs, J. B., C. Y. Hsu, W. L. Terasaki, and G. Brooker (1980) Calcium and microtubule dependence for increased ornithine carboxylase activity stimulated by $\beta$-adrenergic agonists, dibutyryl cyclic AMP, or serum in a rat astrocytoma cell line. Proc. Natl. Acad. Sci. USA 77: 995-999.

Gilad, G. M., and V. H. Gilad (1983) Polyamine biosynthesis is required for survival of sympathetic neurons after axonal injury. Brain Res. 273: 191-194.

Greene, L. A., and J. C. McGuire (1978) Induction of ornithine decarboxylase by nerve growth factor dissociated from effects on survival and neurite outgrowth. Nature 276: 191-193.

Hong, J. S., P. L. Wood, J. C. Gillin, H. Y. T. Young, and E. Costa (1980) Changes of hippocampal met-enkephalin content after recurrent motor seizures. Nature 285: 231-232.

Hong, J. S., T. Kanamatsu, J. F. McGinty, J. Obie, R. S. Dyer, and C. L. Mitchell (1985a) Amygdaloid kindling increases enkephalin-like immunoreactivity but decreases dynorphin A-like immunoreactivity in rat hippocampus. Fed. Am. Soc. Exp. Biol. Abstr. 44: 425.

Hong, J. S., T. Kanamatsu, J. Obic, K. Yoshikawa, and S. Sabol (1985b) Intrastriatal injection of kainic acid increases the abundance of mRNA coding for preproenkephalin A in rat hippocampus. Soc. Neurosci. Abstr. 11: 565.

Hong, J. S., K. Yoshikawa, T. Kanamatsu, J. F. McGinty, C. L. Mitchell, and S. L. Sabol (1985c) Repeated electroconvulsive shocks alter the 
biosynthesis of enkephalin and concentration of dynorphin in the rat brain. Neuropeptides 5: 557-560.

Iadarola, M. J., C. Shin, J. O. McÑamara, and H.-Y. T. Yang (1985) Changes in dynorphin, enkephalin, and cholecystokinin content of hippocampus and substantia nigra after amygdala kindling. Brain Res. 365: 185-191.

Janne, J., and A. Raina (1969) On the stimulation of ornithine decarboxylase and RNA polymerase activity in rat liver after treatment with growth hormone. Biochim. Biophys. Acta 174: 769-772.

Lewis, M. E., J. Laksmanian, J. Nagaiah, P. C. McDonnell, and G. Guroff (1978) Nerve growth factor increases activity of ornithine decarboxylase in rat brain. Proc. Natl. Acad. Sci. USA 75: 10211023.

Morris, G. M., F. J. Seidler, and T. A. Slotkin (1983) Stimulation of ornithine decarboxylase by histamine or norepinephrine in brain regions of the developing rat: Evidence for biogenic amines as trophic agents in neonatal brain development. Life Sci. 32: 1565-1571.

Otani, S., I. Matsui, A. Kuramoto, and S. Morisawa (1985) Induction of ornithine decarboxylase in guinea-pig lymphocytes. Synergistic effect of diacylglycerol and calcium. Eur. J. Biochem. 147: 27-31.

Pajunen, A. E. I., O. A. Hietala, E. L. Virransalo, and R. S. Piha (1978) Ornithine decarboxylase and S-adenosyl-L-methimine decarboxylase in mouse brain: Effect of electrical stimulation J. Neurochem. 30: 281-283.

Pico, R. M., J. Athanikar, K. A. Gilbert, and C. M. Gall (1985) Experimentally induced changes in mossy fiber enkephalin and cholecystokinin content exhibit distinct time courses. Anat. Rec. 211: 154A.

Racine, R. (1972) Modification of seizure activity by electrical stimulation: II. Motor Scizurc. Elcctrocnccphalogr. Clin. Neurophysiol. 32: 281-294.

Russell, D. H., and B. G. M. Durie (1978) Polyamines as markers of normal and malignant growth. In Progress in Cancer Research and Therapy, Vol. 8, pp. 1-78, Raven, New York.

Russell, D. H., and M. K. Haddox (1979) Cyclic AMP-mediated induction of ornithine decarboxylase in normal and neoplastic growth Adv. Enzyme Regul. 17: 61-87.

Russell, D. H., and S. H. Snyder (1968) Amine synthesis in rapidly growing tissues: Ornithine decarboxylase activity in regenerating rat liver, chick embryo, and various tumors. Proc. Natl. Acad. Sci. USA 60: 1420-1428.

Russell, D. H., C. V. Byus, and C. A. Manen (1976) Proposed model of major sequential biochemical events of a trophic response. Life Sci. 19: 1297-1306.

Slotkin, T. A., D. Persons, R. J. Slepeter, D. Taylor, and J. V. Bartolome (1985) Control of nucleic acid and protein synthesis in developing tissucs of the nconatal rat: effects of $\alpha$-difluoromethyl ornithine, a specific inhibitor of ornithine decarboxylase. Teratology 30:211-224.

Tetzlaff, W., and G. W. Kreutzberg (1985) Ornithine decarboxylase in motoneurons during regeneration. Exp. Neurol. 89: 679-688.

White, J. D., C. M. Gall, and J. F. McKelvy (in press) Enkephalin biosynthesis and enkephalin gene expression are increased in hippocampal mossy fibers following unilateral lesion of the hilus. J. Neurosci.

Wolfson, B., R. W. Manning, L. G. Davis, R. Arentzen, and F. Baldino (1985) Co-localization of corticotropin releasing factor and vasopressin in RNA in neurones after adrenalectomy. Nature 315: 5961.

Zetler, G. (1981) Anticonvulsant effects of caerulein, cholecystokinin octapeptides (CCK-8) and diazepam against seizures produced in mice by harman, thioscmicarbazide and isoniazid. Neurosci. Lett. 24: 175182. 